\title{
GCU
}

Glasgow Caledonian

University

University for the Common Good

\section{Urethral bulking agents: a retrospective review of primary versus salvage procedure outcomes}

Daly, Ciara M.E.; Mathew, Jini; Aloyscious, Judey; Hagen, Suzanne; Tyagi, Veenu; Guerrero, Karen L.

Published in:

World journal of urology

DOI:

$10.1007 / \mathrm{s} 00345-020-03413-7$

Publication date:

2021

Document Version

Author accepted manuscript

Link to publication in ResearchOnline

Citation for published version (Harvard):

Daly, CME, Mathew, J, Aloyscious, J, Hagen, S, Tyagi, V \& Guerrero, KL 2021, 'Urethral bulking agents: a retrospective review of primary versus salvage procedure outcomes', World journal of urology, vol. 39, pp. 21072112. https://doi.org/10.1007/s00345-020-03413-7

\section{General rights}

Copyright and moral rights for the publications made accessible in the public portal are retained by the authors and/or other copyright owners and it is a condition of accessing publications that users recognise and abide by the legal requirements associated with these rights.

Take down policy

If you believe that this document breaches copyright please view our takedown policy at https://edshare.gcu.ac.uk/id/eprint/5179 for details of how to contact us. 
TITLE PAGE

URETHRAL BULKING AGENTS: A RETROSPECTIVE REVIEW OF PRIMARY VERSUS SALVAGE PROCEDURE OUTCOMES

4 Authors

Ciara M. E. Daly ${ }^{1}$, Jini Mathew ${ }^{1}$, Judey Aloyscious ${ }^{1}$, Suzanne Hagen ${ }^{1}$, Veenu Tyagi ${ }^{1}$, Karen L. Guerrero ${ }^{1}$

7 Affiliations

${ }^{1}$ Department of Urogynaecology Queen Elizabeth University Hospital, Glasgow

\section{Corresponding Author}




\section{Abstract}

\section{Purpose}

Urethral Bulking Agents (UBA) have traditionally been offered as salvage procedures

19 for recurrent Stress Urinary Incontinence (SUI). We compare the success of UBA in patients

20 that had undergone a previous procedure for SUI (Salvage-UBA) to the SUI surgery naïve

21 (Primary-UBA). We hypothesised a positive effect in both Primary and Salvage-UBA with

22 potentially poorer rates of response in the salvage group.

\section{Methods}

Retrospective case-series of patients having their first UBA (2010-2018).

25 Primary outcome was to assess any difference in patient reported success between groups.

26 Patient reported improvement was assessed on a 4-point scale: 'cured, improved, no change,

27 worse' and treatment 'success' defined as 'cured' or 'improved'.

28 A multivariate analysis, adjusting for plausible differences between groups was undertaken in

29 IBM SPSS Statistics (2016).

\section{Results}

135 Primary-UBA and 38 Salvage-UBA were performed. Complete follow-up was

32 obtained for 114 patients (66\%): 86 Primary \& 28 Salvage. Median follow-up time: 33-months.

33 In 2012, 47\% (8/17) of all UBA were Salvage-UBA, whilst in 2018 the majority were Primary-

34 UBA $(92 \%, 46 / 50)$.

Success was not significantly different between Salvage-UBA 75\% (21/28) versus

36 Primary-UBA 67\% (58/86) $\left(\right.$ Wald $\left.\chi^{2}=0.687, \mathrm{df}=1, \mathrm{p}=0.407\right)$. Top-up rates were similar; $14 \%$

$37\left(n=4 / 28\right.$, Salvage-UBA) versus 15\% $(n=13 / 86$, Primary-UBA $)\left(\chi^{2}=0.011, d f=1, p=0.914\right)$. 


\section{Conclusions}

41 differences were noted for success with Salvage-UBA compared to Primary-UBA.

42

$43 \quad$ Keywords

$44 \quad$ Urethral, Bulking, Incontinence, Primary, Salvage

45

46 


\section{MAIN TEXT}

49 Surgical management of Stress Urinary Incontinence (SUI) is under intense scrutiny. Mesh

50 procedures for SUI were routine until recent years; a current pause is in place within the United

51 Kingdom (UK) (1). Urethral Bulking Agents (UBA) are minimally invasive, non-mesh, day-

52 case or office procedures for SUI. Traditionally, they have been offered as salvage procedures

53 when surgical procedures (e.g. Colposuspension, Autologous Fascial Sling and Mid-Urethral

54 Mesh-Tape) have failed to improve symptoms sufficiently, or when comorbidities make patients

55 unsuitable for these procedures. A Cochrane review (2017) concluded UBA were inferior to

56 surgery for SUI at one-year follow-up but had a better safety profile (2). Despite the inferior

57 success, numbers are on the rise. National statistics from England show a doubling in the

58 number of UBA performed in the last two years (3). For some, UBA may be a desirable first

59 choice procedure for SUI especially if they wish a day-case, non-mesh procedure with a quicker 60 recovery.

61

62 Our aim was to compare the success of UBA in patients that had undergone a previous surgical

63 procedure for Stress Urinary Incontinence (Salvage-UBA) to the SUI surgery naïve (Primary-

64 UBA). We hypothesised a positive effect in both Primary and Salvage-UBA with potentially

65 poorer rates of response in the salvage group.

\section{Methods and Materials}

68 Patients having their first UBA treatment (2010-2018) were identified on departmental audit

69 databases. Trakcare ${ }^{\circledR}$ electronic notes were then reviewed retrospectively and data collected 
70 routinely during standard patient care recorded including: demographics, investigations, agent

71 used, success rates and complications.

73 Diagnosis of SUI was with clinical assessment (positive cough-test with comfortably full

74 bladder) or when clinically indicated, with cystometric finding of Urodynamic Stress

75 Incontinence (USI). Symptomatic Voiding Dysfunction (VD) pre-procedure was defined as the

76 patient complaining of: Slow or Intermittent stream / Hesitancy / Terminal Dribble / Straining.

77 VD at Urodynamics was defined as: Flow rate $<15 \mathrm{mls} /$ second and/or signs of abdominal

78 straining (with or without incomplete emptying). We have taken a Maximum Urethral Closure

79 Pressure (MUCP) of $\leq 30 \mathrm{~cm} \mathrm{H}_{2} 0$ as an indicator of Intrinsic Sphincter Deficiency (ISD) $(4,5)$.

81 UBA were offered under local anaesthesia (LA), in an ambulatory setting.

82 Anaesthesia consisted of topical Instillagel ${ }^{\circledR} 20 \mathrm{ml}$. A further $10 \mathrm{ml}$ of Lidocaine $1 \%$ injected

83 peri-urethrally, at 3 and 9 o'clock positions, was at the discretion of the operating surgeon. Two

84 agents were used within the department over this time period: Polydimethylsiloxane (Trade

85 name: Macroplastique ${ }^{\circledR}$, Manufacturer: Cogentix Medical) was the bulking agent used from

86 2010-2017. Polyacrylamide Hydrogel (PAHG) (Trade name: Bulkamid ${ }^{\circledR}$, Manufacturer:

87 Contura) was introduced in 2016.

88 PAHG was injected trans-urethrally under urethroscopic vision using a 23G x120mm needle

89 surrounded by a rotatable sheath (Bulkamid® system). 1cm markings on the needle aided

90 placement of PAHG blebs 1cm from the urethral orifice. $x 4$ deposits at 2, 5, 7 and 10 o'clock

91 positions were performed ( $2 \mathrm{ml}$ maximum volume), with needle repositioning undertaken to keep

92 sites at the same level/plane to achieve coaptation of the urethra. 
93 Polydimethylsiloxane was administered using an administration device (Macroplastique ${ }^{\circledR}$ - MIS

94 system). Three deposits ( $5 \mathrm{ml}$ maximum volume) were placed at 2, 6 and 10 o'clock positions,

95 trans-urethrally. Trial of void was performed and if residual bladder volumes were less than

$96150 \mathrm{ml}$ (on bladder scan) women were discharged. If there were concerns about VD, patients

97 were taught Clean Intermittent Self Catheterisation (CISC) and discharged. Patients were

98 admitted for intermittent drainage if they were unable to perform CISC.

99 Post-treatment review was conducted by nurse specialists at approximately 3-months. Top-up

100 injections were administered within 3-6 months after the $1^{\text {st }}$ UBA if the patient was not cured of

101 symptoms and $2^{\text {nd }}$ UBA treatments were defined as those occurring $>6$ months from the $1^{\text {st }}$ UBA.

102

103 Primary outcome was the difference in patient-reported success between groups, defined

104 according to patient-reported outcomes on a 4-point scale: cured (defined as no SUI symptoms),

105 improved (defined as sufficiently improved to not wish any alternative surgical treatment), no

106 change (defined as no change or minimal change in symptoms $+/$ - further alternative treatment

107 requested), worse- adapted from the British Society of Urogynaecology (BSUG) audit database

108 (6). Treatment 'success' was defined as cured or improved, assessed at the first clinic follow-up

109 appointment (at approximately 3-months).

110

111 Secondary Outcomes included: ‘top-up’ injection requirement, complications (post-procedure

112 VD, Urinary Tract Infection (UTI) and urethral pain rates), change in Overactive Bladder (OAB)

113 symptoms (cured, improved, no change, worse, new onset), change in the 'International

114 Consultation on Incontinence Questionnaire - Urinary Incontinence Short Form’ (ICIQ-UI SF)

115 scores, duration of treatment success and further management for SUI post UBA therapy. 
117 IBM SPSS version 24 (2016) was used to perform multivariable binary logistic regression 118 modelling to examine the effect of patient type (Primary versus Salvage-UBA) on the outcome 119 of cure or improved (combined to assess 'success') versus no change. The model adjusted for 120 age, bladder symptom type (SUI/ MUI), method of diagnosis (clinical versus urodynamics),

121 operator grade (consultant versus trainee supervised procedure), time to follow-up, and agent 122 used (PAHG versus Polydimethylsiloxane). Variables with a high proportion of missing data

123 (BMI, MUCP and baseline ICIQ-UI SF score) were excluded to maintain analysis validity

124 however none of these variables was individually associated with the outcome in a univariate 125 analysis (see Online Resource 1). Graphpad Prism 8.1.2 was used to assess any differences in 126 secondary outcomes (paired t-test for change in ICIQ-UI SF score, Chi-squared/ Fisher's Exact 127 for categorical data and Mann-Whitney U for data which were not normally distributed.

128 A significance level of 5\% was used throughout.

\section{Results}

132 We identified 173 women over this time period ( $\mathrm{n}=170$ with documented type of agent). 135

133 Primary-UBA and 38 Salvage-UBA were performed. Mean age was 60 years and mean $134 \mathrm{BMI}=30.89 \%$ of procedures were performed under local anaesthesia (2 with concurrent 135 sedation).

136 There has been a greater than four-fold rise in the number of UBA performed on an average of 13711 per year between 2010 and 2016 to 48 per year between 2017 and 2018. Furthermore, in 
1382012 almost half (47\%) of all UBA were salvage-type, whilst in 2018 the majority are Primary-

139 UBA (92\%).

140

141 In the salvage group, patients had undergone a wide range of surgical treatments for SUI

142 (Fig1.docx), including some with multiple previous operations.

144 Patients awaiting follow-up and those who did not attend for follow-up were excluded.

145 Complete follow-up was therefore obtained for 114 patients ( $\mathrm{n}=86$ Primary, n= 28 Salvage).

146 Median follow-up time from date of injection to date of study (October 2018) was 33 months

147 (Interquartile range: 46 months). Median follow-up time for Primary-UBA: 24 months, Salvage-

148 UBA: 56 months.

\section{Primary Outcome}

151 Initial success at follow-up was 75\% versus $67 \%$ in the Salvage-UBA and Primary-UBA groups

152 respectively. Additional data are given in Online Resource 2. In the logistic regression analysis

153 there was no significant association between type of patient (Primary or Salvage-UBA) and the

154 success (cured or improved versus no change) (Wald $\chi 2=0.687, \mathrm{df}=1, \mathrm{p}=0.407$ ) (Table 1 ).

156 Secondary Outcomes

157 Similar top-up rates (second injection) were seen; $14 \%(\mathrm{n}=4 / 28)$ versus 15\% $(\mathrm{n}=13 / 86)$

158 respectively $\left(\chi^{2}=0.011, \mathrm{df}=1, \mathrm{p}=0.914\right)$. Outcomes from top-ups in Primary-UBA: success $\mathrm{n}=5$,

159 no change $n=3$, awaiting FU $n=5$ and Salvage UBA: success=1, no change $n=2$, awaiting $F U$

$160 \mathrm{n}=1$. No patient's symptoms worsened following top-up. 
162 Transient post-procedure VD was higher in the Salvage-UBA group (21\% versus 13\%) but was 163 not statistically significantly different $\left(\chi^{2}=1.384, \mathrm{df}=1, \mathrm{p}=0.239\right)$. Median duration of CISC use 164 was 2.5 days (range 1-14 days) and differed by one day between groups (Primary-UBA: 2 days, 165 Salvage-UBA: 3.5 days).

166 The incidence of VD was highest overall for those who had symptomatic VD pre-operatively 167 ( $\mathrm{n}=12 / 68$; incidence with Primary-UBA 22\%, $\mathrm{n}=11 / 50$ and Salvage-UBA 11\%, n=2/18). In those 168 who were asymptomatic pre-operatively, VD still occurred in $12 \%(n=13 / 105)$ and was higher 169 for those in the salvage group $(30 \%, n=6 / 20)$ compared to the Primary-UBA group $(8 \%, n=7 / 85)$.

170 In women with urodynamic VD, the risk of transient post-operative VD was lower overall at 171 10\%, n=2/21 (Incidence with Primary-UBA: 7\%, n=1/14 and Salvage-UBA: 14\%, n=1/7).

172 Post-procedure VD was not seen in the top-up groups.

173 Following a $2^{\text {nd }}$ treatment course, post-procedure VD overall was 32\% $(n=10 / 32) ; 30 \%(n=3 / 10)$

174 in Salvage-UBA and 32\% $(\mathrm{n}=7 / 22)$ in Primary-UBA cases.

175 Other complications rates were low, namely: UTI $(n=1)$ treated with an oral antibiotic course and 176 transient urethral pain $(n=2)$ at the time of administration was seen in both groups and settled 177 with expectant management rapidly post procedure.

178 No patient reported new or worsening overactive bladder (OAB) symptoms in either group. 7 179 patients did undergo OAB treatment at follow-up; all had prior stress-predominant, mixed 180 urinary incontinence (MUI) and wished to address the OAB component following treatment for 181 SUI and after trying conservative measures. 
183 ICIQ-UI SF questionnaires were poorly completed at 3-month follow-up, allowing only 13 pre 184 and post treatment pairs. Statistically significant reductions in pre and post-treatment ICIQ-UI 185 SF scores were seen overall (Paired t-test $t=4.107, \mathrm{df}=12, \mathrm{p}=0.0015^{*}$ ), although this needs to be 186 interpreted with caution due to the small numbers.

188 Despite any initial success, 36\% $(n=10)$ of Salvage-UBA versus $26 \%(n=22)$ of Primary-UBA 189 ultimately underwent a 2 nd treatment course $\left(\chi^{2}=1.074, \mathrm{df}=1, \mathrm{p}=0.300\right)$. Median time to 2nd 190 treatment course was 11 months: Salvage-UBAs median time was 10 months (interquartile range 191 7-20 months) and 11 months with Primary-UBAs (interquartile range 8-14 months), p=0.635 192 (Mann-Whitney test). 21 completed 3-month follow-up after a $2^{\text {nd }}$ treatment course; overall 193 success was slightly poorer at $62 \%(n=13 / 21), 88 \%(n=7 / 8)$ success with Salvage-UBA versus $19446 \%(n=6 / 13)$ with Primary-UBA. 20 patients proceeded to alternative SUI surgery during the 195 study follow-up: Salvage-UBA (n=8/28, 29\%), Primary-UBA (n=12/86, 14\%) (Fishers Exact, $196 \mathrm{p}=0.908)$. Alternative procedures in the Primary-UBA group included: 4 mid-urethral tapes, 5 197 autologous fascial slings and 3 colposuspension procedures. In the Salvage-UBA group: 3 198 underwent mid-urethral tapes, 4 autologous fascial slings and 1 patient had colposuspension.

200 Discussion

201 We have seen an accelerated use of UBAs which may be due to current government restrictions 202 on transvaginal mesh in this country (1). A UK review into surgical practice highlighted certain 203 criteria to be met prior to lifting restrictions (7). Furthermore, the National Institute for Clinical 204 Excellence (NICE) guidelines (8) advises offering all surgical options and multidisciplinary team 
205 approach. These aspects and the medicolegal environment may have resulted in a shift in 206 treatment preferences.

207 Literature reviews (9-12), of UBAs suggest short-term efficacy is encouraging, however, overall 208 success rates wane over time with repeat injections required. Retrospective studies have shown 209 subjective short-term response with UBA to be 71-84\% for those who have had prior SUI 210 surgery $(13,14)$. This is comparable to rates reported in primary SUI cases $(71-82 \%$ at 6 months 211 and 3 months respectively) $(15,16)$. Reported success is similar to our cases with comparable 212 success for Primary and Salvage-UBA procedures (67-75\%) but with slightly lower success for 213 Primary-UBA. Cure rates in our study (8\%) are lower than published studies however $\geq 2 / 3$ of 214 women were significantly improved to decline further management. Lower cure rate may be due 215 to differences in the populations studied with lower BMI (mean= 25, range 22-27) and younger 216 women (mean= 49 years, range 42-60) in one randomised trial (17). This is in contrast to mean $217 \quad \mathrm{BMI}=30$ and mean age $=60$ years in our study.

218 Particulate UBAs are made from solid microparticles in an absorbable liquid/gel carrier whereas 219 non-particulate UBAs rely on host cells entering the hydrogel to form a network of fibers for 220 anchorage (18). With a constant exchange of water molecules from surrounding tissues, non221 particulate UBAs mechanistically resist absorption (18), staying in place over time.

222 Two agents were used in our study. The first, PAHG (Bulkamid ${ }^{\circledR}$ ) is non-particulate, made of $22397.5 \%$ water and 2.5\% cross-linked polyacrylamide. Studies vary in short term (3-6 month) 224 subjective responder rate when used as a Primary-UBA, ranging from 71\% (16), (19), to 82\% 225 (15). In a study by Sokol et al (20) 12-month follow-up had a 77\% subjective cure/ improvement 226 rate and a $17 \%$ acute urinary retention event rate affecting $5.7 \%$ of patients. 
227 The $2^{\text {nd }}$ agent, Polydimethylysiloxone (Macroplastique ${ }^{\circledR}$ ) has a silicone particulate (2). In a 228 systematic review and meta-analysis by Ghoniem success was 75\% (<6 months) and 64\% (> 229 18months). Typical reinjection rate was 30\% and high reinjection rates were associated with 230 better long-term success (21). In our study, the use of PAHG was more common in the Primary231 UBA group ( 2/3 of cases) than the Salvage-UBA ( 1/2 of cases), reflecting the rise in Primary232 UBA over the last 2 years. The change of agent in 2016 was based on a previous department 233 review (22), showing high reinjection rates due to early recurrence of symptoms (30\%).

234 Notably, agent type did not contribute to any significant differences in outcomes between groups 235 in the logistic regression analysis.

236 Studies have varied in timing of and the terms used in reporting repeat injections. Pai and Al237 Singury (15) reported 'no booster was offered when there was no improvement but good 238 coaptation at surgery’. The Standard Operating Procedure for PAHG suggests if a 'top-up' is 239 required to improve treatment efficacy, this can be carried out at 4-6 weeks following $1^{\text {st }}$ 240 injection. Other studies $\left((19,20)\right.$ have reported $2^{\text {nd }}$ and $3^{\text {rd }}$ reinjection requirement rates (not 241 using 'top-up'), with a $2^{\text {nd }}$ injection rate of 35\% at 6-8 weeks following $1^{\text {st }}$ UBA (19) and a $3^{\text {rd }}$ 242 injection rate of $35.8 \%$ if not dry after $1^{\text {st }}+/-2^{\text {nd }}$ bulking (repeat injections administered at a mean 24335 days after previous injections) (20). Standardisation of follow-up assessment points and 244 reporting would allow better comparisons of outcomes across studies.

245 In this study salvage-UBA tended to lose more effect over time with $36 \%$ vs $26 \%$ of Primary246 UBA proceeding to have a $2^{\text {nd }}$ treatment course. These were repeated at about one year and 247 results did not reach statistical significance between groups. 
248 The rate of voiding dysfunction in this study (15\%) is higher than previously reported. Most of

249 our procedures are performed under LA in ambulatory care. A strict local policy with early

250 recourse to CISC (PVR $>150 \mathrm{ml}$ ), may have impacted on our results.

251 This was a single-institution, retrospective study which did not have a control group.

252 Additionally, primary outcome was assessed at 3 months (short-term). We do acknowledge that

253 these are sources of potential bias and limitations of our study. ICIQ-UI SF was poorly

254 completed post-procedure, which is being addressed locally.

255 Objective assessment with urodynamics post-procedure has been used when reporting outcomes

256 for UBA, however, has tended to show more favourable success. Subjective patient responses

257 capture the crucial impact on quality of life for the patient which we have used in this study - this

258 is arguably more important (12).

259

260 Overall, this study reports a moderate subjective success (67-75\%) for both Primary and

261 Salvage-UBAs with no significant differences in success between these groups, however, further

262 work is needed. The number of women opting for UBA has increased substantially with $92 \%$ of

263 procedures performed as primary SUI procedures in 2018. With the uptake in UBA as a primary

264 choice, follow-up of any impact on future SUI surgical procedures has not been established.

265 More than ever, long-term outcomes should be a priority for all UBA research. These will

266 inform patient safety with UBA and aid counselling on the success longevity for these agents.

268 DECLARATIONS

269

$270 \quad$ Funding 
$271 \quad$ Nil received

272

273 Availability of data and material

274 Not available

275

276 Consent to participate

277 Not applicable given study design

278

279 Consent for publication:

280 Not applicable

281

282 Code availability

283 Not available

284

285 Conflicts of interest

286 Authors JM and JA have no conflicts of interest. Authors CMED, VT and KLG have received

287 funding/sponsorship from Contura Ltd. for attendances at educational conferences \& meetings.

288

289 Ethics approval

290 In view of the retrospective nature of the study and all the procedures being performed were part

291 of the routine care, this study did not meet requirements for ethical approval according to the

292 Health Research Authority decision tool.

293 


\section{Authors' contributions}

295 Daly C. M. E: Project development, Analysis of Results, Manuscript writing/ editing.

296 Aloyscious J: Data collection, Manuscript editing.

297 Mathews J: Data collection, Manuscript editing.

298 Hagen S: Data Analysis, Manuscript editing.

299 Tyagi V: Project Development \& Manuscript editing.

300 Guerrero K. L: Project development, Manuscript writing/ editing.

301

302

303 CAPTIONS

304 Fig.1 Type of Previous Stress Urinary Incontinence Procedure in the Salvage-UBA group

305 Table 1. Multivariable Logistic Regression Analysis

306 Online Resource 1. Univariate analysis of BMI, MUCP and ICIQ-UI SF variables on primary

307 outcome

308 Online Resource 2. Primary Outcome for Primary and Salvage-UBA groups

309

310 


\section{REFERENCES}

317

318 1. Medicines and Healthcare products Regulatory Authority. Pause on the use of vaginally

319 inserted mesh for stress urinary incontinence [Internet]. United Kingdom: GOV.UK; [cited 2018

320 July 17]. Available from URL:https://www.gov.uk/government/news/pause-on-the-use-of-

321 vaginally-inserted-surgical-mesh-for-stress-urinary-incontinence

322 2. Kirchin V, Page T, Keegan PE, Atiemo KO, Cody JD, McClinton S, et al. Urethral injection

323 therapy for urinary incontinence in women. Cochrane Database of Systematic Reviews. [Online]

324 2017;7(7): CD003881. Available from: doi:10.1002/14651858.cd003881.pub4

325 3. Zacche MM, Mukhopadhyay S, Giarenis I. Changing surgical trends for female stress urinary

326 incontinence in England. International Urogynecology Journal. [Online] 2019;30(2): 203-209.

327 Available from: doi:10.1007/s00192-018-3839-4

328 4. Smith PP, Leijsen SAL van, Heesakkers JPFA, Abrams P, Smith ARB. Can we, and do we

329 need to, define bladder neck hypermobility and intrinsic sphincteric deficiency?: ICI-RS 2011.

330 Neurourology and Urodynamics. [Online] 2012;31(3): 309-312. Available from:

331 doi:10.1002/nau.22220

332 5. Krissi H, Pansky M, Halperin R, Langer R. Maximal urethral closure pressure < 20 cm H2O:

333 does it predict intrinsic sphincteric deficiency? The Journal of reproductive medicine.

334 2005;50(11): 824-826.

335 6. Moran P, Foon R, Assassa P. The BSUG national database: concept, design, implementation

336 and beyond. The Obstetrician \& Gynaecologist. [Online] 2013;15(2): 120-127. Available from:

337 doi:10.1111/tog.12004 
7. IMMDS. First do no harm -The report of the Independent Medicines and Medical Devices

339 Safety (IMMDS)Review. [Online] 2020 Aug p. 1-277. Available from:

340 https://www.immdsreview.org.uk/downloads/IMMDSReview_Web.pdf

341 8. NICE Guidance - Urinary incontinence and pelvic organ prolapse in women: management.

342 BJU International. [Online] 2019;123(5): 777-803. Available from: doi:10.1111/bju.14763

343 9. Li H, Westney OL. Injection of Urethral Bulking Agents. Urologic Clinics of North America.

344 [Online] 2019;46(1): 1-15. Available from: doi:10.1016/j.ucl.2018.08.012

345 10. Hussain SM, Bray R. Urethral bulking agents for female stress urinary incontinence.

346 Neurourology and Urodynamics. [Online] 2019;38(3): 887-892. Available from:

347 doi:10.1002/nau.23924

348 11. Kasi AD, Pergialiotis V, Perrea DN, Khunda A, Doumouchtsis SK. Polyacrylamide hydrogel

349 (Bulkamid®) for stress urinary incontinence in women: a systematic review of the literature.

350 International Urogynecology Journal. [Online] 2016;27(3): 367-375. Available from:

351 doi:10.1007/s00192-015-2781-y

352 12. Mohr S, Siegenthaler M, Mueller MD, Kuhn A. Bulking agents: an analysis of 500 cases and 353 review of the literature. International Urogynecology Journal. [Online] 2013;24(2): 241-247.

354 Available from: doi:10.1007/s00192-012-1834-8

355 13. Dray EV, Hall M, Covalschi D, Cameron AP. CAN URETHRAL BULKING AGENTS

356 SALVAGE FAILED SLINGS? Urology. [Online] 2018;(Obstet Gynecol 1112 Pt 1 2008).

357 Available from: doi:10.1016/j.urology.2018.09.019

358 14. Zivanovic I, Rautenberg O, Lobodasch K, Bünau G von, Walser C, Viereck V. Urethral

359 bulking for recurrent stress urinary incontinence after midurethral sling failure. Neurourology

360 and Urodynamics. [Online] 2017;36(3): 722-726. Available from: doi:10.1002/nau.23007 
361 15. Pai A, Al-Singary W. Durability, safety and efficacy of polyacrylamide hydrogel

362 (Bulkamid $\left.{ }^{\circledR}\right)$ in the management of stress and mixed urinary incontinence: three year follow up

363 outcomes. Central European Journal of Urology. [Online] 2015;68(4): 428-433. Available

364 from: doi:10.5173/ceju.2015.647

365 16. Lose G, Sørensen HC, Axelsen SM, Falconer C, Lobodasch K, Safwat T. An open

366 multicenter study of polyacrylamide hydrogel (Bulkamid $\left.{ }^{\circledR}\right)$ for female stress and mixed urinary

367 incontinence. International Urogynecology Journal. [Online] 2010;21(12): 1471-1477.

368 Available from: doi:10.1007/s00192-010-1214-1

369 17. Freitas A-MI, Mentula M, Rahkola-Soisalo P, Tulokas S, Mikkola TS. Tension-Free Vaginal

370 Tape Surgery versus Polyacrylamide Hydrogel Injection for Primary Stress Urinary

371 Incontinence: A Randomized Clinical Trial. The Journal of urology. [Online] 2019;203(2): 372-

372 378. Available from: doi:10.1097/ju.0000000000000517

373 18. Chapple C, Dmochowski R. Particulate Versus Non-Particulate Bulking Agents In The

374 Treatment Of Stress Urinary Incontinence. Research and Reports in Urology. [Online]

375 2019;Volume 11: 299-310. Available from: doi:10.2147/rru.s220216

376 19. Toozs-Hobson P, Al-Singary W, Fynes M, Tegerstedt G, Lose G. Two-year follow-up of an

377 open-label multicenter study of polyacrylamide hydrogel (Bulkamid ${ }^{\circledR}$ ) for female stress and

378 stress-predominant mixed incontinence. International Urogynecology Journal. [Online]

379 2012;23(10): 1373-1378. Available from: doi:10.1007/s00192-012-1761-8

380 20. Sokol ER, Karram MM, Dmochowski R. Efficacy and Safety of Polyacrylamide Hydrogel

381 for the Treatment of Female Stress Incontinence: A Randomized, Prospective, Multicenter North

382 American Study. The Journal of Urology. [Online] 2014;192(3): 843-849. Available from:

383 doi:10.1016/j.juro.2014.03.109 
384 21. Ghoniem GM, Miller CJ. A systematic review and meta-analysis of Macroplastique for 385 treating female stress urinary incontinence. International Urogynecology Journal. [Online] 386 2013;24(1): 27-36. Available from: doi:10.1007/s00192-012-1825-9

387 22. Scott V, Tyagi V, Guerrero K. Bladder Neck Injections for Stress Urinary Incontinence; A 388 Retrospective Cohort Study. [Online] 2016. Available from: https://www.ics.org/2016/slot/15935 389 